ESJ Social Sciences

\title{
The Impact of Exchange Rate on Ethiopia's Coffee Export
}

\author{
Solomon Tewelde Argaie, M.S.c \\ College of Public Administration, \\ Nanjing Agricultural University, Nanjing, China
}

Doi:10.19044/esj.2021.v17n23p27

Submitted: 22 February 2021

Accepted: 02 July 2021

Published: 31 July 2021
Copyright 2021 Author(s)

Under Creative Commons BY-NC-ND

4.0 OPEN ACCESS

Cite As:

Argaie S.T. (2021). The Impact of Exchange Rate on Ethiopia's Coffee Export. European Scientific Journal, ESJ, 17(23), 27. https://doi.org/10.19044/esj.2021.v17n23p27

\begin{abstract}
Although coffee constitutes the largest share of exports, producers in Ethiopia have historically received a small percentage of the export revenue from the price of green coffee. Reasons often mentioned are heavy government intervention and high marketing and processing costs. Before 1992, government regulation of the domestic coffee market in the form of fixed producer prices and the Ethiopian Coffee Marketing Corporation's monopoly power put a substantial wedge between the producer price and the world price of coffee by imposing an implicit tax on producers. Having liberalized the market and adopted a floating exchange rate regime to boost exports (coffee) as the country struggles with foreign exchange shortages, not much has improved in exports (coffee) or foreign reserve availability. This paper utilizes monthly data from 2010-2015 to develop a multiple regression model to determine the impact the exchange rate has on coffee export if there is any. The empirical findings indicate that the exchange rate is not significant in determining or influencing exports but the prices of the two famous coffee types (Arabica and Robusta). Corroborated by the research outcome, we suggest that policymakers do not rely on the depreciation or devaluation of the ETB (Ethiopian Birr) as a tool for export promotion and growth.
\end{abstract}

Keywords: Coffee exports, Currency depreciation, Arabica price, Robusta price 


\section{Introduction}

Ethiopia is the birthplace or the origin of the coffee plant and culture. More so, it is known to have the best coffee more than that from Italy or Columbia. Coffee production has been a longstanding tradition in Ethiopia, which dates back to dozens of centuries ago. The central coffee plants produced here include coffee Arabica and Robusta. As the geographic origin of Arabica type of coffee, the nation exports a substantial amount of coffee where exports in 2010 reached 3.3 million 60-kilogram bags (Petit, 2007). Thus, it is the heartbeat of Ethiopia's agricultural economy. Ethiopia is among the world's largest coffee growers and producers, at number five, and the largest in Africa, producing about three to five percent of the world's coffee every year. Today, over 12 million individuals in the country rely on the coffee industry for their livelihood and growth. The internationally adored beverage has grown to be a vital part of Ethiopia's culture (Goodwin, 2020). Nevertheless, it is appropriate to say that, regardless of the high sales of coffee, various drivers or factors highly affect Ethiopia's coffee exports.

Ethiopia is known to be the birthplace of coffee. The legend has it that the country's nomadic mountain tribes discovered the plant and beans and their stimulating effect in the $9^{\text {th }}$ century (Degaga, 2020). The commercialization of coffee beans started in the 1950s when the Ethiopian government established a system for grading and classifying coffee and later developed the National Coffee Board of Ethiopia (NCBE) to help the farmers sell and export coffee provided opportunities for individuals to develop and grow (Yassin, 2020). It is their primary source of income for many Ethiopian citizens. Fortunately, coffee movements and cooperatives like Sidama Coffee Farmers' Cooperative Union (SCFCU) help small-scale farmers to sell their products. Apart from the massive government-run coffee estates, about 98\% of the nation's product is cultivated by small landowners (Mugwe, 2014). Coffee is grown in Ethiopia's four regions, including Sidamo, Harrar, Ghimbi, and Limu, were farmers major in farming coffee. Here, it is crucial to add that Ethiopia boasts producing and exporting various blends and brands ranked among the best coffees globally. These coffees include Yirdgacheffe, Ethiopian Harrar, Ethiopian Sidamo, Ethiopian Limu, Djimmah Coffee, and Lekempti (Degaga, 2020).

\section{Problem Statement:}

Coffee is Ethiopia's most prominent export crop making it central to its economy (Petit, 2020), where it contributes to $60 \%$ of Ethiopia's foreign export income. However, this percentage has been on the decline, a change caused by various issues experienced by the coffee export sector. Over the past few decades, the country has also experienced increased political turbulence, leading to dissatisfaction and unrest and threatened its coffee industry. 
Numerous environmental, economic and social issues affect the country, wavering the coffee farmers' confidence and dedication to cultivating coffee. This may also affect the quality and quantity of coffee production.

The Ethiopian coffee sales are highly dependent on international prices and are profoundly affected by the current world coffee market. Nevertheless, the global coffee market has changed drastically in the last few decades. Changes in the worldwide policy environment, technological changes, new arrangements in supply chain and demand, and the asymmetrical character of power in the coffee value chain increasingly reduce the opportunities for vulnerable and growing economies to secure the benefits experienced through feasible coffee trade (Petit, 2007). Reliable coffee markets in developing countries such as Ethiopia support poverty reduction and economic development. These factors, in addition to consumer or social behavior, productivity, inflation, currency exchange rates, and demand, greatly influence the market and export of Ethiopian coffee.

Before 1992, government regulation of the domestic coffee market in the form of fixed producer prices and the Ethiopian Coffee Marketing Corporation's monopoly power put a substantial wedge between the producer price and the world price of coffee by imposing an implicit tax on producers (Amamo, 2014). Having liberalized the market and adopted a floating exchange rate regime to boost coffee exports as the country struggles with foreign exchange shortages, not much has improved in exports (coffee) or foreign reserve availability. The problem is that it is unclear how exchange rates usually affect coffee exports in Ethiopia. Various factors or determinants for coffee exports are explored in the literature review. However, this research aims to examine if exchange rates usually influence or affect Ethiopia's coffee exports, either by increasing or reducing the export ratios.

\section{Impact of Exchange Rates}

Ethiopia has experienced liberalization, incorporating essential changes in both the nominal and real exchange rates. According to Wondemu and Potts (2016), exports in Ethiopia have increased more than the GDP, illustrating that exports contribute and lead to the growth of an economy and a nation entirely. The study thoroughly explored how the real exchange rate affects export performance and suggests that the country should maintain highly competitive real exchange rates to improve its export performance and diversify its exportable. Wondemu and Potts (2016) illustrate overvaluation as harmful, while undervaluation of real exchange rate enhances export supply and diversification. Thus, a high percentage of growth in exports is connected to periods of undervalued currencies. More importantly, it suggests that the difference in export performance between Ethiopia and other countries is profoundly influenced by differences in real exchange rate policies in specific 
countries. Based on these findings, real exchange rates in Ethiopia could impact coffee exports in Ethiopia.

Muluneh (2018) also evaluated the impact of exchange rate volatility on Ethiopian coffee export. It employed annual time series data obtained from the nation's different institutions, including the Ministry of Finance and economic development (MOFED), National Bank of Ethiopia (NBE) Ethiopian Custom Authority (ECA). It used a Bounds testing and Auto aggressive Distributed Lag (ARDL) model to develop a long-term relationship between exchange rate volatility and coffee export in Ethiopia. Muluneh (2018) illustrates that coffee exports in the nation have a negative but crucial relationship with exchange rate volatility. On the contrary, trade openness and real effective exchange rate positively and significantly influence coffee exports. The impacts of exchange rates on coffee exports in Ethiopia are further to be studied in this research.

Nevertheless, Muluneh et al. (2018) recommend policymakers in Ethiopia retain a well-managed, stable, and effective exchange rate regime to increase exports and attract more foreign direct investments. Muluneh's findings are similar to those obtained by Mehare and Edriss (2013), which explored the effects of exchange rate variability and gross domestic product on Ethiopia's main export crop, coffee. It found that exchange rate variability has negative impacts on coffee exports in the short-term but has insignificant effects in the long-term. This means that exchange rate changes in the nation favor coffee export performance, but this is yet to be verified in this research.

Exchange rate policies are crucial for the economic performance of countries. Tamru, Minten, and Swinnen (2021) state that countries that have successfully export agricultural products usually avoid overvaluation of their currencies as more competitive exchange rates result in enhanced external balances. Misalignment of exchange countries in countries such as Ethiopia leads to distortions to agricultural incentives, often at the expense of export agriculture, leading to fewer benefits, significantly if the exchange rates influence market conditions. The research suggests that better exchange rate alignment via the standard prescription enhances external balances and incentivize export agriculture. Nevertheless, Tamru, Minten, and Swinnen (2021) believe that coffee exporters are willing to take losses while exporting the product by offering high prices for the product locally to attract foreign exchange markets. This would help increase coffee prices and the profits gained by the farmers. As viewed from the previous literature, different research explores the determinants for coffee exports in Ethiopia. This research, however, aims to explore how exchange rates influence or affect coffee exports in Ethiopia. 


\section{Research Methodology:}

\subsection{Theoretical Framework}

The theoretical framework of this study follows but not precisely investigating the Marshall-Lerner condition and the J-curve. While the theory addresses the response of the balance of trade to fluctuations in the exchange rate, this research narrowly investigates the impact of the exchange rate fluctuations on coffee exports with special focus on Ethiopia. The following derivations were obtained from Stern (1973). In that derivation, the author identified trade

$$
\begin{gathered}
B_{f} \equiv p_{f x} X-p_{f m} M \\
\Delta B_{f} \equiv\left(p_{f x} \Delta X+X \Delta p_{f x}\right)-\left(p_{f x} \Delta M+M \Delta p_{f x}\right) \\
V_{f x} \equiv p_{f x} X \ldots \ldots \ldots \text { foreign value of exports } \\
V_{f x} \equiv p_{f x} M \ldots \ldots \ldots \text { foreign value of imports }
\end{gathered}
$$

balance in foreign currency term to follow the outlined definition:

$$
\Delta B_{f} \equiv V_{f x}\left(\frac{\Delta X}{X}+\frac{\Delta p_{f x}}{p_{f x}}\right)+V_{f m}\left(\frac{\Delta M}{M}+\frac{\Delta p_{f m}}{p_{f m}}\right)
$$

However, when a country devalued its domestic currency (currency depreciation), this leads to:

In line with the above, we continue to accommodate the value of export and import by defining

$$
e_{x} \equiv \frac{\Delta X}{X} / \frac{\Delta p_{f x}}{p_{f x}=\text { home export supply elasticity }}
$$

each under the following conditions:

By rearranging and substituting the above equations into equation (2) we have:

$$
\begin{aligned}
\eta_{x} & \equiv-\frac{\Delta X}{X} / \frac{\Delta p_{f x}}{p_{f x}}=\text { foreign export demand elasticity } \\
e_{m} & \equiv \frac{\Delta M}{M} / \frac{\Delta p_{f m}}{p_{f m}}=\text { foreign import supply elasticity } \\
\eta_{m} & \equiv \frac{\Delta M}{M} / \frac{\Delta p_{f m}}{p_{f m}}=\text { =home import demand elasticity }
\end{aligned}
$$

From the above equation, we can then continue to invoke the elasticities of demand and supply of import and export. In this equation we apply the negative demand elasticities to allow us to have a positive equation as follows: 
In the light of the above, it is expected that foreign currency and home currency should relate as a result of the ensuing exchange rate $r$ and this will us to have:

$$
\begin{gathered}
p_{f m} \equiv p_{k m} r \\
p_{f m}+\Delta p_{k m}=\left(p_{k m}+\Delta p_{k m}\right) r(1-k) \\
\Delta p_{f m}=\left(p_{k m}+\Delta p_{k m}\right) r(1-k)-p_{k m} r \\
\Delta p_{k m}=p_{k m} r-p_{k m} r k+\Delta p_{k m} r k-p_{k m} r \\
\Delta p_{k m}=-p_{k m} r+\Delta p_{k m} r-\Delta p_{k m} r k \\
\frac{\Delta p_{f m}}{p_{f m}}=-k+\frac{\Delta p_{k m}}{p_{k m}}(1-k) \\
\frac{\Delta p_{f x}}{p_{f x}}=-k+\frac{\Delta p_{k x}}{p_{k x}}(1-k)
\end{gathered}
$$

Next to the above, we assume home currency to be devaluated by a proportion of $\mathrm{k}$, and this will make the home currency to be worth $\mathrm{r}(1-\mathrm{k})$ unit of foreign currency, as a result of this development, the level of price changes can be seen as follows:

From our definition of elasticity and substituting equation (6)-(9) into equation (15)-(16) will allow us to have the following:

Figure 2. graphical representation of Marshall-Lerner conditions for domestic currency and foreign currency

Showing domestic demand for imports

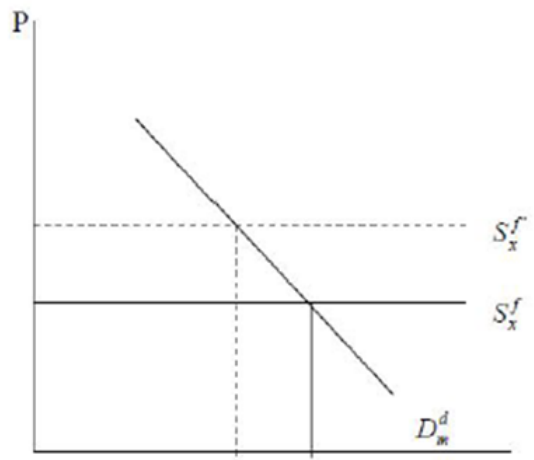

showing domestic demand for exports

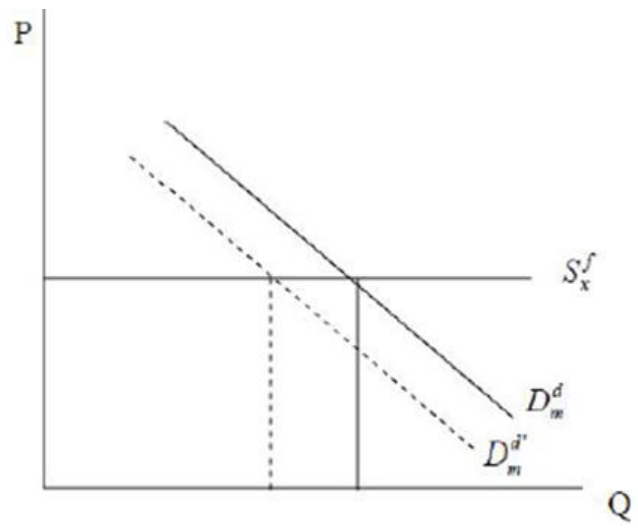



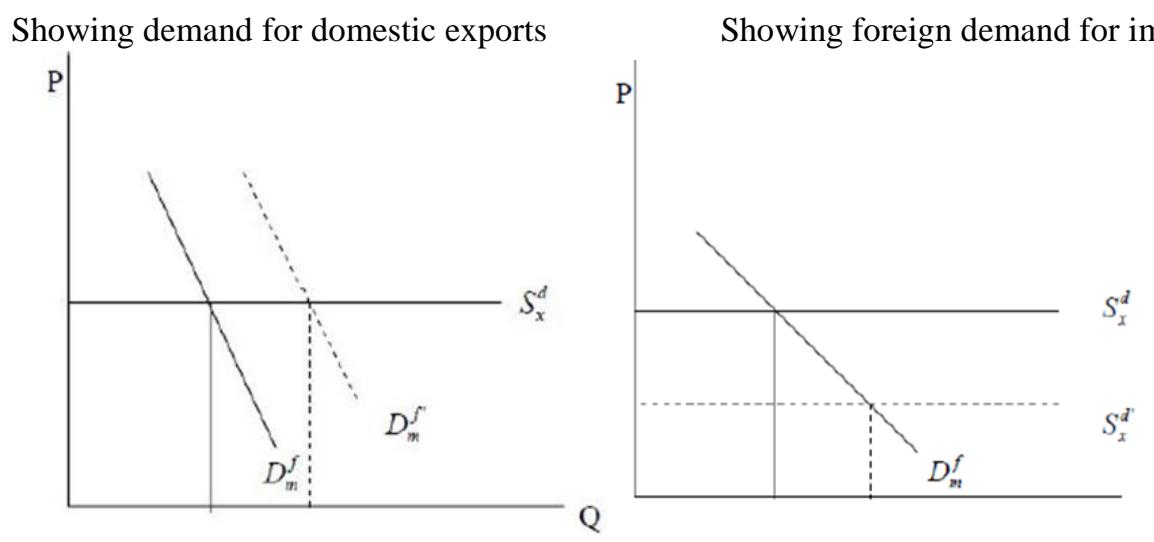

Q

\subsection{Empirical Methodology}

\subsection{Data and Variables:}

This paper uses monthly time series data for the period 2010-2015 and 1980-2017 obtained from the UN Comtrade database. The study utilizes data of coffee exports, bilateral exchange rate of the ETB (Ethiopian Birr against USD), international market prices of arabica and Robusta coffee.

The empirical analysis is derived from a final parsimonious model, selected through the iterative selection method also called general to specific method. The model uses coffee exports as the dependent variable and the exchange rate, market prices of Arabica and Robusta coffee as the regressors. The main regressor however, is the exchange rate as we set to investigate whether it is significant in determining the volume of coffee export.

\subsection{Transformation and Study Hypothesis:}

In other to eliminate trends and non-stationarity, the data is transformed by taking the natural the first difference of the variables. To ensure that the variables are stationary, we ran the Augmented Dicky-Fuller (ADF) test on the first difference at the 95 percent confidence level. The results of the ADF test produced t-statistics greater than the 5-percent critical value leading us to reject the null hypothesis of non-stationarity. This is an indication that the variables are integrated of the order I (1).

In addition to the ADF test, we conducted the Johansen test for cointegration to ascertain the right model specification and regression technique. Evaluating the outcome of the trace and max statistics at the 5percent critical value, the Johansen test results suggest that the variables are not cointegrated. Having taken the first difference of the first variables, we ran the selection order criteria, we found no lag relationship among the variables allowing us to estimate the model by simple OLS method. Validated by the pre-estimation tests, we estimate a multiple linear regression model for import determination, in a forward selection method. The purpose of this empirical 
study is to examine whether the exchange rate has a significant impact on the export of coffee. In other words, we try to answer the question whether the exchange rate is a significant determinant of the direction of coffee export?

The hypotheses are formulated around the primary variable of interest, the exchange rate.

Export model hypothesis:

$H_{0}$ : the ETB exchange rate has a significant impact on coffee exports (significant positive relationship)

$H_{1}$ : the ETB exchange rate has no significant impact on coffee exports is not causing exports to increase (negative or no significant relationship)

\begin{tabular}{r|crc} 
Source & SS & df & MS \\
\hline Model & $6.5370 \mathrm{e}+15$ & 3 & $2.1790 \mathrm{e}+15$ \\
Residual & $4.1395 \mathrm{e}+16$ & 43 & $9.6267 \mathrm{e}+14$ \\
\hline Total & $4.7932 \mathrm{e}+16$ & 46 & $1.0420 \mathrm{e}+15$
\end{tabular}

\begin{tabular}{r|rrrrrr}
\hline cofexval & Coef. & Std. Err. & $t$ & $\mathrm{e}>|\mathrm{t}|$ & [958 Conf. Interval] \\
\hline dexrate & 3713968 & 5692701 & 0.65 & 0.518 & -7766457 & $1.52 e+07$ \\
darabicapr & $-2.73 e+07$ & $1.19 e+07$ & -2.29 & 0.027 & $-5.13 e+07$ & -3306878 \\
drobustapr & $8.16 e+07$ & $3.26 e+07$ & 2.50 & 0.016 & $1.58 e+07$ & $1.47 e+08$ \\
_cons & $7.43 e+07$ & 4602364 & 16.15 & 0.000 & $6.50 e+07$ & $8.36 e+07$ \\
\hline
\end{tabular}

\section{Results and Discussion:}

$$
\text { Coff } \exp =\beta_{0}+\beta_{1} \Delta e_{\text {rate }}+\beta_{2} \text { arabicapr }+\beta_{3} \Delta \text { robustapr }+\varepsilon
$$

$$
\text { Coff } \exp =\beta_{0}+\beta_{1} \text { arabicapr }+\beta_{2} \text { robustap }+\varepsilon
$$

\begin{tabular}{r|crc} 
Source & SS & df & MS \\
\hline Model & $6.1272 e+15$ & 2 & $3.0636 e+15$ \\
Residual & $4.1805 e+16$ & 44 & $9.5010 e+14$ \\
\hline Total & $4.7932 e+16$ & 46 & $1.0420 e+15$
\end{tabular}

$$
\begin{array}{lrr}
\text { Number of obs } & = & 47 \\
\mathrm{E}(2, \quad 44) & = & 3.22 \\
\text { Prob }>\text { E } & =0.0493 \\
\text { R-squared } & =0.1278 \\
\text { Adj R-squared } & =0.0882 \\
\text { Root MSE } & = & 3.1 e+07
\end{array}
$$

\begin{tabular}{r|rrrrrr}
\hline cofexval & Coef. & Std. Err. & $t$ & $\mathrm{P}>|\mathrm{t}|$ & [95\% Conf. Interval] \\
\hline darabicapr & $-2.60 \mathrm{e}+07$ & $1.16 e+07$ & -2.23 & 0.031 & $-4.94 e+07$ & -2494814 \\
drobustapr & $8.19 e+07$ & $3.24 \mathrm{e}+07$ & 2.53 & 0.015 & $1.66 e+07$ & $1.47 e+08$ \\
_cons & $7.48 e+07$ & 4524724 & 16.52 & 0.000 & $6.56 e+07$ & $8.39 e+07$ \\
\hline
\end{tabular}

Result Interpretation:

Following a general to a specific model selection process which is based mainly on the values of $t$ and F-statistics, we decide on the final parsimonious model. The general regression output indicates that all the regressors are statistically significant and that the population parameters of $\beta_{2}$ and $\beta_{3}$ 
significantly different from zero except for the exchange rate variable (exrate), which, according to the statistic is not significant. Therefore, by the iterative selection process, we drop the exchange rate and re-run the regression. The resultant of the second regression produces a significant model relative to the first one. Citing the $\mathrm{F}$ and $\mathrm{t}$-statistic values, the final model has an overall significance of 3 percent relative to the 2 percent of the first model, and significant predictors. In simpler expressions, this interpretation entails that the exchange rate has no impact in any degree to influence the direction of coffee exports. That is, regardless of how much the currency depreciates, it does not significantly lead to export growth or promotion. One explanation as provided in the literature review, is that, even though Ethiopia remains among the top coffee exporter, it follows Brazil and Vietnam who do not only produce the same type of coffee but are emerging market economies (Brazil). in addition, these countries may not have strong currencies against the US Dollar, making exchange rate policy ineffective to drive export growth.

Another important outcome indicated by the regression output worth taking note of, is the negative relationship between coffee exports and price of the arabica coffee type. Many factors could be responsible for this. Although the regression model is a multiple linear regression, there are still some factors omitted and included in the error term. One of the possible reasons for this negative relationship is the substitution effect. Given historical data, Arabica's price has slightly been higher than Robusta's price, even though the two differ in terms of quality and taste, and an increment in the price of Arabica from a top coffee exporting country, means an increment in price across the board. Holding the exchange rate and other factors constant, this may trigger an increase in demand for Robusta, it even worsens if the ETB (Ethiopian Birr) remains relatively stronger against other currencies of top coffee exporters.

Given the output of the regression analysis, we reject the null hypothesis that the exchange rate has a significant impact on the direction of coffee exports. Theoretically, it is an important determinant of coffee export, but it may just be those other complementary factors to make it more effective which are not captured in our model.

\section{Discussion}

Ethiopia is viewed as the birthplace of coffee and the origin of coffee culture. It is one of the largest coffee producers worldwide, falling in fifth after countries like Brazil and Vietnam. Considering that coffee sales mostly rely on exports to international markets and countries that do not engage in coffee production, it was imperative to conduct research investigating factors or issues that influence coffee exports. The study focused on exploring if exchange rates affect Ethiopian coffee exports. Previous literature presents Ethiopia as a nation that produces the best quality coffee globally. 
Nevertheless, this does not guarantee a market for its product since other countries produce similar coffee types, especially Arabica.

Various factors influence coffee exports, including trade policies, access to international markets, export supply, demand, high transaction costs, actors and processes therein, price risks, productivity in the fields, quality control, and coffee smuggling occurrences. Nevertheless, while some studies found that currency exchange rates affect coffee exports in Ethiopia, this study found that exchange rates do not significantly affect coffee exports. These findings are similar to Gebreyesus's (2015) study outcomes which found that real exchange rates do not affect coffee exports both in the short- and longterm. In other words, the exchange rate has no impact or relevance in changing the direction of coffee exports in Ethiopia. Despite the changes in currency exchange rates, depreciation or appreciation, it does not impact or lead to coffee export growth or promotion.

Also, there is a negative relationship between coffee exports and the price of arabica coffee caused by various factors. One factor that could explain the negative relationship is the substitution effect. Arabica coffee has had the highest market price throughout time than Robusta, mainly because they differ in quality and taste. This means that if the price of Arabica in Ethiopia increases, the costs of other coffee types also increase. More importantly, the increment triggers an increase in demand for Robusta and other types of coffee. Nevertheless, no evidence shows that exchange rates between different currencies, including the Ethiopian Birr, the US Dollar, and the Euro, affect prices or the amount of coffee exported to other countries.

Therefore, as demonstrated in the outcome section, we derive that currency exchange rates do not influence Ethiopia's coffee exports. The exchange rate could be a crucial factor in the coffee market, with complementary factors making it more or less influential, but they are not explored in this research. While coffee remains Ethiopia's main export product, the government should try to make policies that promote social and consumer buying behaviors, increase productivity, and address inflation to increase market and export potential for Ethiopian coffee.

\section{Conclusion}

In recent years the country's dependence on coffee as the primary earner of foreign exchange has increased. This dependence has been evidenced by how government requires access to foreign exchange for its survival. Coffee is thus of fundamental importance in the Ethiopian case. This survival may take the form of enabling citizens to exercise preferences through being able to import capital and consumer goods from abroad; it may be through official servicing of past debt or the ability to take on new debts. More 
bluntly, it may allow importing defense equipment that the government in power uses to control internal dissent.

Despite its positive strides in growth and economic development, the Ethiopian economy is still largely agriculturally dominated if environmental and climatic conditions remain relatively normal. This also means the chunk of its vast population depends on agriculture for their livelihood. Coffee is the largest component of the agricultural sector output and consequently the largest share of Ethiopia's export. While Ethiopia is a top exporting coffee country, it still faces competition from Brazil and Vietnam, which rank first and second. It produces and exports the same Arabica and Robusta types globally, which are the two leading dominant coffee brands.

Over the years, the government has adopted several different measures to promote export growth, especially coffee. This includes liberalization of the domestic coffee market by relinquishing government monopoly and devaluation of the currency at some point regardless of its gradual depreciation. In this paper, we investigated whether the depreciation of the ETB (increase in the ETB/USD) exchange rate negatively or positively impacts coffee exports. Our empirical evidence leads us to conclude that the exchange rate has no significant impact on the direction of coffee exports but the prices themselves.

Even though the government directs or leads the coffee market, coffee production in Ethiopia is still concentrated in small-scale scattered farmers who often find it difficult to attract good prices and increase profitability. Therefore, we suggest that the government increase its role in organizing and structuring coffee production, encouraging processing and value-adding, and distributing to international markets.

\section{References:}

1. Amamo, A. A. (2014). Coffee production and marketing in Ethiopia. Eur J Bus Manag, 6(37), 109-22.

2. Boansi, D., \& Crentsil, C. (2013). Competitiveness and determinants of coffee exports, producer price, and production for Ethiopia. Journal of Advanced Research in Economics and International Business, 1(1), 31-56.

3. Deribe, H. (2019). Review on Factors which Affect Coffee (Coffea Arabica L.) Quality in South Western, Ethiopia. International Journal of Forestry and Horticulture, 5(1), 12-19.

4. Degaga, J. (2020). Review on Coffee Production and Marketing in Ethiopia.

5. Gebreyesus, T. (2015). Determinants of coffee export performance in Ethiopia. Journal of Economics and Sustainable Development, 6(5), 147-158. 
6. Goodwin, L. (2020). Ethiopian coffee culture. The Spruce Eats. https://www.thespruceeats.com/ethiopian-coffee-culture-765829

7. Mehare, A., \& Edriss, A. K. (2013). Evaluation of the Effect of Exchange Rate Variability on the Export of Ethiopia's Agricultural Product: A Case of Coffee. Margin: The Journal of Applied Economic Research, 7(2), 171-183.

8. Muluneh, A. (2018). Effect of exchange rate volatility on Ethiopian coffee export.

AAU-ETD Home. https://etd.aau.edu.et/handle/123456789/13045

9. Mugwe, J. W. (2014). Factors Influencing Coffee Production By Small Scale Farmers: A Case Of Tetu Constituency, Kenya (Doctoral dissertation, University of Nairobi).

10. Petit, N. (2007). Ethiopia's coffee sector: A bitter or better future? Journal of Agrarian Change, 7(2), 225-263.

11. Tadele, M. (2013). Ethiopian Coffee Exports: Development Performance, Challenges, and Prospects (Doctoral dissertation, ST. MARY'S UNIVERSITY).

12. Tadesse, T., Tesfaye, B., \& Abera, G. (2020). Coffee production constraints and opportunities at major growing districts of southern Ethiopia. Cogent Food \& Agriculture, 6(1), 1741982.

13. Tamru, S., Minten, B., \& Swinnen, J. (2021). Trade, value chains, and rent distribution with foreign exchange controls: Coffee exports in Ethiopia. Agricultural Economics, 52(1), 81-95.

14. Wondemu, K. A., \& Potts, D. J. (2016). The impact of the real exchange rate changes on export performance in Tanzania and Ethiopia. 